\title{
Clinical and fiberoptic endoscopic assessment of swallowing in patients with chronic obstructive pulmonary disease
}

\author{
Marina Rodrigues Bueno Macri', Jair Mendes Marques², Rosane Sampaio Santos ${ }^{3}$, Ana Maria Furkim , Irinei Melek5, \\ Daniel Rispoli', Maria Cristina de Alencar Nunes ${ }^{7}$.
}

1) Speech Therapist. Masters in Communication Disorders from the University of Paraná Tuiuti.

2) Degree in Mathematics. Doctorate in Geodetic Sciences from the Federal University of Paraná (HC-UFPR)

3) Speech Therapist. Student Doctorate in Internal Medicine from the HC-UFPR

4) Speech Therapist. Doctorate in Human Communication Disorders from the Federal University of Sao Paulo.

5) Doctor. Pulmonologist.

6) Doctor. Otolaryngologist.

7) Speech Therapist. Student Doctorate in Internal Medicine from the HC-UFPR

Institution: University of Paraná Tuiuti.

Curitiba / PR - Brazil.

Mailing address: Marina Rodrigues Bueno Macri - Rua Saldanha da Gama 86, apt. 42b - Curitiba / PR - Brazil - Zip code: 80060-170 - E-mail: buenomarina405@ hotmail.com Article received on January $17^{\text {th }}, 2013$. Article accepted on April $7^{\text {th }}, 2013$

\section{SUMMARY}

Introduction: Chronic obstructive pulmonary disease is characterized by progressive and partially reversible obstruction of pulmonary airflow.

Aim: To characterize swallowing in patients with chronic obstructive pulmonary disease and correlate the findings with the degree chronic obstructive pulmonary disease, heart and respiratory rate, oxygen saturation, and smoking.

Method: We conducted a prospective cohort study of 19 patients (12 men and 7 women; age range, 50-85 years) with confirmed medical diagnosis of chronic obstructive pulmonary disease. This study was performed in 2 stages (clinical evaluation and functional assessment using nasolaryngofibroscopy) on the same day. During both stages, vital signs were checked by medical personnel. Results: Clinical evaluation of swallowing in all patients showed the clinical signs of cough. The findings of nasolaryngofibroscopy highlighted subsequent intraoral escape in 5 patients (26.5\%). No patient had tracheal aspiration. There was no association of subsequent intraoral escape with degree of chronic obstructive pulmonary disease, heart and respiratory rate, oxygen saturation, or smoking.

Conclusion: In patients with chronic obstructive pulmonary disease, there was a prevalence of oral dysphagia upon swallowing and nasolaryngofibroscopy highlighted the finding of subsequent intraoral escape. There was no correlation between intraoral escape and the degree of chronic obstructive pulmonary disease, heart and respiratory rate, oxygen saturation, or smoking. Keywords: Pulmonary Disease, Chronic Obstructive; Deglutition Disorders; Respiration; Smoking; Heart Rate; Respiratory Rate.

\section{INTRODUCTION}

Chronic obstructive pulmonary disease (COPD) is characterized by progressive and partially reversible airway obstruction. This airflow obstruction is associated with an abnormal inflammatory response of the lungs and occurs between $5 \%$ and $15 \%$ of the adult population (1-3) and is a leading cause of death worldwide. Smoking is responsible for more than $90 \%$ of the cases, with a prevalence of disease found in men (4).

The diagnosis of COPD should be considered in the presence of cough, sputum production, dyspnea, and a history of exposure to risk factors such as smoking, environmental pollution, and occupational exposure to toxic gases or particles (1).

Several factors can lead to inadequate food intake in patients with COPD, causing weight loss, oropharyngeal dysphagia (possibly due to difficulty in chewing), dyspnea, cough, fatigue, and secretion (5).

Oropharyngeal dysphagia is a swallowing disorder with specific signs and symptoms that are characterized by alterations at any stage and/or between the steps of the dynamics of swallowing; this condition may be congenital or acquired $(6,7)$. Stable dysphagic patients with COPD can present important clinical complications such as malnutrition, pulmonary complications, dehydration, and discomfort when eating $(8,9)$.

In patients with oropharyngeal dysphagia, clinical evaluation of swallowing associated with instrumental evaluation techniques such as nasolaryngofibroscopy (FEES) (10) is required, which assists in the application of therapeutic approaches.

The present study aimed to characterize swallowing 
in patients with COPD and correlate the findings of swallowing with the degree of COPD, heart and respiratory rate, oxygen saturation, and smoking.

\section{METHOD}

A prospective cohort study was performed in 19 patients with confirmed diagnosis of COPD. Seven patients (40.0\%) were female and 12 patients (60.0\%) were male. Patient age ranged between 50 and 85 years, with a mean of 66.7 years. This study was approved by the research ethics committee of our institution (No. OF. CEP Hospital Angelina Caron 42/09). Subjects signed a consent form after being informed of the objectives, procedures, and responsibilities of the study, as well as receiving answers to any questions regarding the study.

Inclusion criteria included patients of both genders aged over 50 years with a diagnosis of COPD according to the GOLD scale (11), who had not used inhaled medication up to $4 \mathrm{~h}$ before evaluations, and were smokers and nonsmokers. Patients with a lowered level of consciousness and clinically unstable patients were excluded from the study.

The time for COPD diagnosis was 5.7 years on average, with a minimum of 2 months, a maximum of 12 years, and a standard deviation of 10.0 years. Of the 19 patients, $14(75.0 \%)$ were smokers with a mean duration of smoking of 41.1 years and a standard deviation of smoking of 5.0 years. The remaining 5 patients (25.0\%) had never smoked.

The study was conducted in 2 stages on the same day. Patients referred to the pulmonology clinic with a clinical diagnosis of COPD were transferred to the otolaryngology clinic of the same hospital, where the tests were conducted. The first stage consisted of clinical evaluation of swallowing and the second stage consisted of functional assessment of swallowing using FEES (10), with vital signs being checked by the medical team during both assessments.

During the first stage, the protocol data for clinical evaluation of swallowing used in our hospital were followed. The clinical signs of aspiration (cough, dyspnea, and "wet" voice) were recorded (12). The food consistencies used (liquid, nectar, honey, pudding, and solid) followed the pattern of the American Dietetic Association (ADA) (13). For this evaluation, patients completed a sequence of 3 swallows (free swallow, $5 \mathrm{~mL}$, and $10 \mathrm{~mL}$ ) for each food consistency. Swallowing function was evaluated by uptake of the bolus, closing of the lips, preparation of the bolus, subsequent extraoral exhaust, waste in the oral cavity, throat clearing, and coughing reflex. After evaluation, the Functional Oral Intake Scale (FOIS) (14) was applied to assess the level of food intake of each patient.

During the second stage, FEES (10) was performed by otolaryngologists following the protocol data for FEES evaluation of swallowing used in our hospital. We used the same consistency of foods offered during the clinical evaluation of swallowing function, plus the inorganic dye aniline blue to contrast with the pink color of the mucosa. During examination, the presence of exhausted intraoral posterior pharyngeal residue in the posterior pharyngeal wall, epiglottic vallecula, and piriform sinus as well as pharyngeal clearance (number of swallows needed for clearance) and laryngeal penetration or tracheal aspiration (with or without reflex cough) were observed. The Severity Scale for Dysphagia: Penetration and Aspiration (15) was applied to the results.

\section{RESULTS}

Regarding respiratory impairment, 16 patients (85.0\%) were in ambient air and 3 patients (15.0\%) were oxygen dependent, one (5.0\%) with 2 liters of oxygen, one (5.0\%) with 3 liters of oxygen, and one (5.0\%) with 5 liters of oxygen. Regarding breathing pattern, 4 patients (20.0\%) had wheezing, 1 (5.0\%) showed mouth breathing, 4 (20.0\%) were mixed, 1 (5.0\%) had tachypnea, and 9 (50.0\%) had dyspnea.

Upon clinical evaluation of swallowing, all patients showed clinical signs of cough. Regarding food intake, all 19 patients (100.0\%) were at level 7 (oral full and unrestricted) of the FOIS. FEES findings indicated that exhausted intraoral posterior residue prevailed in 5 patients (26.5\%) and no patient had tracheal aspiration. Residue in the epiglottic vallecula occurred in 1 patient (5.0\%) with liquid and in 2 patients (10.5\%) with solid food, both with bleaching.

At the significance level of 0.05 , there was no significant relationship between subsequent intraoral escape and the degree of COPD, heart and respiratory rate, oxygen saturation, or smoking, which can be observed in Tables 1, 2, 3, 4, and 5, respectively. The Severity Scale for Dysphagia: Penetration and Aspiration score was 1 (contrast does not enter the airway) in all 19 patients (100.0\%).

\section{DISCUSSION}

Defining the incidence of oropharyngeal dysphagia in patients with COPD, as well as the identification of possible risk factors, may be useful in the management and 
Table I. Relationship between the degree of copd and intraoral escape.

\begin{tabular}{|c|c|c|c|c|c|c|}
\hline \multirow[t]{3}{*}{ COPD GRADE } & \multicolumn{6}{|c|}{ INTRAORALESCAPE } \\
\hline & \multicolumn{2}{|c|}{ Pudding } & \multicolumn{2}{|c|}{ Liquid } & \multicolumn{2}{|c|}{ Solid } \\
\hline & A & $P$ & A & $P$ & A & $\mathrm{P}$ \\
\hline$\|$ & $2(10.5 \%)$ & - & I (5.0\%) & I (5.0\%) & $2(10.5 \%)$ & - \\
\hline III & $8(42.5 \%)$ & I (5.0\%) & $9(47.5 \%)$ & - & 7 (37.0\%) & $2(10.5 \%)$ \\
\hline IV & $7(37.0 \%)$ & | (5.0\%) & $6(31.5 \%)$ & $2(10.5 \%)$ & $5(26.0 \%)$ & $3(16.0 \%)$ \\
\hline$p$ & \multicolumn{2}{|c|}{0.6784} & \multicolumn{2}{|c|}{0.3756} & \multicolumn{2}{|c|}{0.3359} \\
\hline
\end{tabular}

$\mathrm{COPD}=$ chronic obstructive pulmonary disease, $\mathrm{A}=$ absent, $\mathrm{P}=$ present.

Fisher's test at a significance level of 0.05 .

Table 2. Relationship between heart rate and intraoral escape.

\begin{tabular}{|c|c|c|c|c|c|c|}
\hline \multirow{3}{*}{$\begin{array}{l}\text { HR } \\
\text { (bpm) }\end{array}$} & \multicolumn{6}{|c|}{ INTRAORALESCAPE } \\
\hline & \multicolumn{2}{|c|}{ Pudding } & \multicolumn{2}{|c|}{ Liquid } & \multicolumn{2}{|c|}{ Solid } \\
\hline & A & $P$ & A & $P$ & A & $P$ \\
\hline Less than 80 & $2(10.5 \%)$ & I (5.0\%) & $3(16.0 \%)$ & - & $2(10.5 \%)$ & I (5.0\%) \\
\hline 80-89 & 7 (37.0\%) & - & 7 (37.0\%) & - & $6(31.5 \%)$ & I (5.0\%) \\
\hline 90-99 & $6(31.5 \%)$ & - & $3(16.0 \%)$ & $3(16.0 \%)$ & $5(26.5 \%)$ & | (5.0\%) \\
\hline 100 or more & $2(10.5 \%)$ & I (5.0\%) & $3(16.0 \%)$ & - & | (5.0\%) & $2(10.5 \%)$ \\
\hline $\mathrm{p}$ & \multicolumn{2}{|c|}{0.7368} & \multicolumn{2}{|c|}{0.0867} & \multicolumn{2}{|c|}{0.4443} \\
\hline
\end{tabular}

$\mathrm{HR}=$ heart rate, $\mathrm{bpm}=$ beats perminute, $\mathrm{A}=$ absent, $\mathrm{P}=$ present.

Fisher's test at a significance level of 0.05 .

Table 3. Relationship between respiratory rate and intraoral escape.

\begin{tabular}{|c|c|c|c|c|c|c|}
\hline \multirow{3}{*}{$\begin{array}{l}\text { RR } \\
\text { (bpm) }\end{array}$} & \multicolumn{6}{|c|}{ INTRAORALESCAPE } \\
\hline & \multicolumn{2}{|c|}{ Pudding } & \multicolumn{2}{|c|}{ Liquid } & \multicolumn{2}{|c|}{ Solid } \\
\hline & $A$ & $P$ & $A$ & $P$ & $A$ & $P$ \\
\hline $\begin{array}{l}\text { Less than } 17 \\
17-18 \\
19 \text { or more }\end{array}$ & $\begin{array}{l}7(37.0 \%) \\
8(42.5 \%) \\
2(10.5 \%)\end{array}$ & $\begin{array}{c}- \\
\text { I (5.0\%) } \\
\text { I (5.0\%) }\end{array}$ & $\begin{array}{l}7(37.0 \%) \\
6(31.5 \%) \\
3(16.0 \%)\end{array}$ & $3(16.0 \%)$ & $\begin{array}{c}7(37.0 \%) \\
6(31.5 \%) \\
1(5.0 \%)\end{array}$ & $\begin{array}{c}-\overline{-} \\
3(16.0 \%) \\
2(10.5 \%)\end{array}$ \\
\hline p & \multicolumn{2}{|c|}{0.3860} & \multicolumn{2}{|c|}{$\quad 0.2270$} & \multicolumn{2}{|c|}{0.0681} \\
\hline
\end{tabular}

$R R=$ respiratory rate, $b p m=$ breaths per minute,$A=$ absent,$P=$ present.

Fisher's test at a significance level of 0.05 .

Table 4. Relationship of oxygen saturation with intraoral escape.

\begin{tabular}{|c|c|c|c|c|c|c|}
\hline \multirow{3}{*}{$\begin{array}{l}\mathrm{O}_{2} \text { SATURATIO } \\
(\mathrm{mmH})\end{array}$} & \multicolumn{6}{|c|}{ INTRAORALESCAPE } \\
\hline & \multicolumn{2}{|c|}{ Pudding } & \multicolumn{2}{|c|}{ Liquid } & \multicolumn{2}{|c|}{ Solid } \\
\hline & A & $P$ & A & $P$ & A & $P$ \\
\hline Less than 80 & I (5.0\%) & I (5.0\%) & $2(10.5 \%)$ & - & I (5.0\%) & I (5.0\%) \\
\hline $80-89$ & $2(10.5 \%)$ & - & $2(10.5 \%)$ & - & | (5.0\%) & | (5.0\%) \\
\hline 90 or more & $14(73.5 \%)$ & | (5.0\%) & $12(64.0 \%)$ & $3(16.0 \%)$ & $12(64.0 \%)$ & $3(16.0 \%)$ \\
\hline & \multicolumn{2}{|c|}{0.3860} & \multicolumn{2}{|c|}{0.4696} & \multicolumn{2}{|c|}{0.2722} \\
\hline
\end{tabular}

$\mathrm{O}_{2}=$ oxygen, $\mathrm{A}=$ absent, $\mathrm{P}=$ present.

Fisher's test at a significance level of 0.05 .

Table 5. Relationship between smokers and non-smokers and intraoral escape.

\begin{tabular}{|c|c|c|c|c|c|c|}
\hline \multirow[t]{3}{*}{ GROUP } & \multicolumn{6}{|c|}{ INTRAORALESCAPE } \\
\hline & \multicolumn{2}{|c|}{ Pudding } & \multicolumn{2}{|c|}{ Liquid } & \multicolumn{2}{|c|}{ Solid } \\
\hline & A & $\mathrm{P}$ & A & P & $\mathrm{A}$ & P \\
\hline $\mathrm{TAB}$ & $12(63.5 \%)$ & $2(10.5 \%)$ & $12(65.0 \%)$ & $2(10.0 \%)$ & $10(55.0 \%)$ & $4(20.0 \%)$ \\
\hline NTAB & $5(26.0 \%)$ & - & $4(20.0 \%)$ & I (5.0\%) & $4(20.0 \%)$ & | (5.0\%) \\
\hline p & \multicolumn{2}{|c|}{0.5322} & \multicolumn{2}{|c|}{0.6244} & \multicolumn{2}{|c|}{0.6026} \\
\hline
\end{tabular}

$\mathrm{TAB}=$ smoker, $\mathrm{NTAB}=$ non-smoker, $\mathrm{A}=$ absent, $\mathrm{P}=$ present.

Fisher's test at a significance level of 0.05 . 
prevention of complications resulting from this disease, assisting in the control of morbidity and mortality and cost reduction (16).

When the results of a previous study were corrected for smoking, the risk for chronic bronchitis became equal for men and women (17). In the current study of 19 patients, $60.0 \%$ were male and $73.5 \%$ had contact with smoke or were smokers, which is similar to results found in the literature.

Dyspnea is the most common symptom of COPD, and is a term used to characterize the subjective experience of respiratory distress. There is a correlation between COPD and swallowing disorders, which shows that breathing during swallowing is halted and resumed predominantly in the inspiratory phase, increasing the risk of aspiration (18). Cough can be considered as a variable parameter in clinical evaluation, since it can be present in both COPD and dysphagia. The presence of this symptom in patients with oropharyngeal dysphagia, regardless of form or intensity, is a warning sign of the presence of potential tracheal aspiration, especially when it is associated with food. This kind of aspiration increases the risk of aspiration pneumonia, regardless of the mechanism of action.

In the present study, posterior intraoral escape was the variable most commonly found in patients during FEES. This finding is related to motor impairment of swallowing, and the longer the delay in firing the swallowing reflex, the greater the chance of aspirating part of the bolus, since the airway remains open $(19,20)$.

The presence of food residues in the epiglottic vallecula and/or piriform sinus can occur because of changes in the preparatory phase and/or oral swallowing, inefficiency of the ejection bolus, delayed triggering of the swallowing reflex, a decrease in peristalsis, reduced laryngeal elevation, or anterior and/or incoordination of the cricopharyngeal muscle (21).

Since the presence of the characteristic symptoms of COPD affects the quality of life of these patients, we chose to correlate symptoms including degree of COPD, heart and respiratory rate, oxygen saturation, and smoking with intraoral exhaust with a view to subsequent observation of the impact of swallowing on worsening of pulmonary symptoms. Patients with COPD have impaired swallowing and a greater risk of aspiration pneumonia when compared with healthy patients (22).

Patients with COPD have abnormal autonomic control of cardiac function and this study corroborates the research in question (23).
The lack of coordination between swallowing and breathing increases the risk of aspiration in tachypneic or dyspneic patients, since they may not be able to tolerate longer periods or even short periods of apnea during swallowing. The normal respiratory rate based on a normal adult ranges from 12 to 20 breaths per minute (24).

In the current study, it was observed that for pudding and liquid food consistencies, $10.5 \%$ of patients had posterior intraoral escape, but for solid food consistency, $21.0 \%$ of patients had subsequent intraoral escape. There have been no previous studies on this association published in the literature. When cough is a major symptom during clinical evaluation of patients with COPD, it is evident that instrumental assessment is important for a more accurate diagnosis. With the evolution of disease, patients with COPD develop a profile of dysphagia, and the cough reflex should be taken into consideration by the audiologist as a possible sign of swallowing disorders (12).

The role of the speech therapist in multidisciplinary teams is effective in dysphagic patient outcomes, and their early intervention allows regress of the increased risk of dysphagia in patients with COPD. The late identification of swallowing disorders can lead to severe pulmonary complications associated with aspiration (25).

With health care programs aimed at recognition by professionals involved in the care of patients with COPD, the signs and symptoms of swallowing disorders can be incorporated into multidisciplinary care.

\section{CONCLUSION}

In this study, it was concluded that patients with COPD showed no oropharyngeal dysphagia upon clinical evaluation of swallowing. FEES revealed that there was a prevalence of oral dysphagia with the finding of subsequent intraoral escape. There was no relationship between subsequent intraoral escape and the degree of COPD, heart and respiratory rate, oxygen saturation, or smoking.

\section{REFERENCES}

1. Pauwels RA, Buist S, Calverley PMA, Jenkins CR, Hurd SS Global strategy for the diagnosis, management, and prevention of chronic obstructive pulmonary disease nhlbi/ who global initiative for chronic obstructive lung disease (gold) workshop summary. Am J. Respir. Crit. Care Med. 2001;163(5):1256-76.

2. Menezes A, Perez-Padilla R, Jardim Jr, et al. Chronic obstructive pulmonary disease in five Latin American cities 
(the PLATINO study): a prevalence study. Lancet. 2005;366(9500):1875-81.

3. Mannino DM, Holguin F. Epidemiology and global impact of chronic obstructive pulmonary disease. Semin Respir Crit Care Med. 2005;26(2):204-10

4. Campos HS. O preço da DPOC. Pulmão RJ. 2003;12(4): 5-7.

5. Mueller D. Terapia clínica nutricional na doença pulmonar. In: Mahan LK, Stump SE. Krause - Alimentos, nutrição e dietoterapia. 10th ed. São Paulo: Roca; 2002. p. 789-805.

6. American Speech and Hearing Association (ASHA) (2004) [internet]. Model medical review guidelines for dysphagia services [monograph on the Internet]. [Revision to DynCorp 2001 FTRP by ASHA]. [cited 2007 Mar 3]. Available from: http://www.asha.org/NR/rdonlyres/5771BOF7 D7C04D47832A86FC6FEC2AE0/0/DynCorpDysph

7. Michou E, Hamdy S. Cortical input in control of swallowing. Curr Opin Otolaryngol Head Neck Surg. 2009; 17(3):166-71.

8. Rabe KF, Hurd S, Anzueto A, et al. Global Initiative for Chronic Obstructive Lung Disease: Global strategy for the diagnosis, management and prevention of chronic obstructive pulmonary disease: GOLD executive summary. Am J Respir Crit Care Med. 2007;176(6):532-55.

9. Wedzicha JA, Seemungal TA. COPDexacerbations: defining their cause and prevention. Lancet. 2007;370(9589):786-96.

10. Langmore S, Schatz K, Olsen N. Fiberoptic endoscopic examination of swallowing safety: a new procedure. Dysphagia. 1988;2(4):216-9.

11. Global strategy for the diagnosis, management, and prevention of chronic obstructive pulmonary disease: Executive summary 2006. Global Initiative for Chronic Obstructive Lung Disease (GOLD) [Internet]. Available from http://www.goldcopd.org.

12. Marik P. Aspiration pneumonitis and aspiration pneumonia. N Engl J Med. 2001;344(9):665-71.

13. American Dietetic Association (ADA). Food and nutrition misinformation: position of ADA. J. Amer Diet Assoc. 2002;102(2):260-6.
14. Crary M, Mann G, Groher M. Initial psychometric assessment of a functional oral intake scale for dysphagia in stroke patients. Am J Phys Med Rehab. 2005;86(8):151620

15. Rosenbek JC, Robbins J, Roecker EB, Coyle JL, Wood JL. A penetration aspiration scale. Dysphagia. 1996;11(2):93-8.

16. Skoretz S, Rebeyka D. Dysphagia following cardiovascular surgery: a clinical overview. CanJ Cardiovasc Nurs. 2009;19(2):10-6.

17. Menezes AM, Victora CG, Rigatto M. Prevalence and risk factors for chronic bronchitis in Pelotas, RS, Brazil: a population-based study. Thorax. 1994;49(12):1217-21.

18. Shaker R, Li Q, Ren J, et al. Coordination of deglutition and phases of respiration: effect of aging, tachypnea, bolus volume, and chronic obstructive pulmonary disease. AJP. 1992;263(5):750-5.

19. Langmore SE, Schatz K, Olson N. Endoscopic and videofluoroscopic evaluations of swallowing and aspiration. Ann Otol Rhinol Laryngol. 1991;100(8):678-81.

20. Helfrich-Miller KR, Rector KL, Straka JA. Dysphagia: its treatment in the profoundly retarded patient with cerebral palsy. Arch Phys Med Rehabil. 1986;67(8):520-5.

21. Costa M, Moscovici M, Pereira AA, Koch HA. A avaliação videofluoroscópica da transição faringoesofágica (esfíncter superior do esôfago). Radiol. Bras. 1993;26(2):71-80.

22. Aviv JE, Sacco RL, Thomson J, et al. Silent laryngopharyngeal sensory deficits after stroke. Ann Otol Rhinol Laryngol. 1997;106(2):87-93.

23. Paschoal MA, Petrelluzzi KF, Gonçalves NV. Estudo da variabilidade da frequência cardíaca em pacientes com doença pulmonar obstrutiva crônica. Rev. Ciênc. Méd. 2002;11(1):27-37.

24. Porto CC. Exame clínico: bases para a prática médica. 5th ed. Rio de Janeiro: Guanabara Koogan; 2004.

25. SmithardDG, O`Neill PA, Parks C, Morris J. Complications and outcome after acute stroke: does dysphagia matter? Stroke. 1996;27(7):1200-4. 